\title{
Education and retirement: does University education at mid-age extend working life?
}

\author{
Anders Stenberg $^{1 *}$ and Olle Westerlund ${ }^{2}$
}

\author{
* Correspondence: \\ anders.stenberg@sofi.su.se \\ ${ }^{1}$ SOFI, Stockholm University, \\ SE-10691, Stockholm, Sweden \\ Full list of author information is \\ available at the end of the article
}

\begin{abstract}
To our knowledge, this paper provides the first study evaluating the effects of higher education for adults on the timing of retirement. Using detailed longitudinal population register data 1982-2010, we track first-time enrollees in higher education in 1992-1993. Our sample is aged $42-55$ at the time of enrollment and thus aged 60-73 in 2010. We find that higher education increases labor market survival rates when aged $61-66$ by about 5 percentage points. The estimates represent relatively large effects. Tentative calculations indicate that if enrollment occurs at age 42 , the retirement delay represents about one percent in yearly earnings returns per year of tertiary education.

JEL classification: $\mathrm{H} 52, \mathrm{H} 55, \mathrm{I} 28$

Keywords: Human capital; Education; Labor supply; Retirement; Pensions
\end{abstract}

\section{Introduction}

The OECD and the EU have encouraged governments to stimulate retraining of older workers (OECD 1998, 2001, EU 2007, 2008), reflecting a widespread view that inadequate educations constitute an important reason for early retirement. Indeed, several kinds of research results have implied that high skilled are less likely to leave full-time employment and less sensitive to labor market fluctuations (Peracchi and Welch 1994, Blau 2005, Maestas and Zissimopoulos 2010, Blau and Goodstein 2010) ${ }^{1}$. The suggested underlying mechanisms include direct effects in terms of improved matching to market demand of skills, complementarities between formal education and on-the-job -training (Fouarge and Schils 2009), that technological changes favor high skilled workers as they are more likely to receive on-the-job-training (Bartel and Sicherman 1993, Brunello 2003,Arulampalam et al. 2004), and/or that education affects health and thereby explain prolonged labor force participation (Kalwij and Vermeulen 2005). These studies all consider education completed at a young age, providing what may appear as reasonable basis that education for adults postpone the timing of retirement. However, there is no direct empirical evidence supporting the hypothesis, presumably as it requires access to very long time-series of data on earnings, pensions and other indicators of labor force status, as well as data on adult education ${ }^{2}$. In addition, the theoretical predictions are ambiguous as education may increase individuals' life time income streams from both earnings and pensions. The effect on the timing of retirement then depends on the individuals' time preferences and/or the relation between 
income from work and pension entitlements, with workers postponing retirement as long as the option value of remaining in the work force is positive (Stock and Wise 1990). The theoretical ambiguity gives empirical studies an important role for our understanding of if and/or how educational investments influence the timing of retirement. To the best of our knowledge, we provide the first analysis of retirement behavior of adults who invest in formal higher education.

The purpose of this paper is to study whether adult education (henceforth $\mathrm{AE}$ ) at tertiary level starting at age 42 or later delays decisions to retire. The analysis is based on Swedish population register data which include information on registration in higher education since 1977, on annual earnings 1982-2010, and on retirement pension payments 1990-2010. To control for the endogeneity of the decision to enroll AE, we use propensity score matching, exploiting very detailed data which includes annual earnings ten years prior to enrollment, information on family characteristics, sector of employment and transfers related to unemployment, sick-leave, social welfare and early retirement. In robustness checks, we consider potential unobservable confounders such as systematic differences in time horizons and pre-program dynamics in earnings and transfers, but the overall implications of our results remain stable ${ }^{3}$.

Earlier studies of adults aged 40 or above in formal education have generally found positive effects on earnings when enrolling community college in the US (Jacobson et al. 2005a, b) or upper secondary education in Sweden (Stenberg and Westerlund 2008, Stenberg et al. 2011). Regarding the timing of retirement, Stenberg et al. (2012) reported no effects of upper secondary schooling completed at age 42 or higher. Neither males nor females who enrolled in Swedish upper secondary education 19861989, when aged 42-55, differ in their timing of retirement relative to matched comparisons, observed up and until 2004 when aged 60-73. This result holds across a variety of subgroups.

We have found only two other studies addressing whether adult educational investments affect the timing of retirement. Kristensen (2012) considers a hybrid between formal education and on-the-job training and Battistin et al. (2013) examine on-the-job training. Kristensen (2012) analyzes government co-sponsored training in Denmark for individuals born 1936-1944. This type of training was very prevalent during the period 1980-2004, which the data of the study covers, because if training took place during work hours, the government reimbursed the equivalent of the unemployment insurance benefits of the participant. About 40 percent of the individuals were at some point in training, "usually" encompassing less than two weeks of courses. The results indicate no significant effects of post-secondary courses on the timing of retirement, and significant but small effects following basic education or vocational courses. Translated to one year of full time training, this effect corresponds to about a one month extension of working life. Battistin et al. (2013), in contrast, reports a notable delay in retirement following on-the-job-training in Italy. They exploit exogenous variation in both mandatory minimum early retirement age and government regional training subsidies during the 1990s and early 2000s, reporting that an extra month of on-the-job-training reduces the probability of retirement by 5 percent. The authors consider the estimated effect on labor force participation to be substantial.

The contribution of the present study is that we examine the effects of formal tertiary/higher education on the timing of retirement. Our results indicate that higher 
education significantly delays retirement, and thus differ from the zero effect of low skilled in formal schooling found in Stenberg et al. (2012). The difference in findings are possibly explained by the "job polarization" hypothesis (Goos and Manning 2007), suggesting that the demand for medium skilled performing routine tasks has dropped relatively to the demand for labor in the tails of the skill distribution. The premium for medium-skilled upgrading to high-skilled may then be higher compared with that of low-skilled making the transition to mid-skilled ${ }^{4}$.

In the following, we provide a description of the institutional framework for $\mathrm{AE}$ in Sweden and a presentation of data. The empirical model and our identification strategy are outlined in Section 3 while Section 4 contains the results. The findings are summarized and discussed in Section 5.

\section{Institutional setting, data and descriptive statistics}

To stimulate participation and the demand for education among adults, employees in Sweden are since 1974 legally entitled to be on leave for studies and afterwards be reinstated with equal working conditions and wages. Participants are also eligible for financial support of about $€ 1000$ per month (2010 values), sufficient for a modest level of consumption. One third of the funding must be repaid within 25 years from the year the studies have been completed. Education is generally publicly funded and free of charge but a few programs are in excess demand with admittance then decided by grades from the final (third or fourth) year of upper secondary education. However, pre-enrollment tests provide an alternative route to qualify and in the 1990s working life experience gave extra grade points. If one also considers the vast supply of decentralized tertiary level education, offered in about 30 cities in a total population of 9 million, virtually all individuals with a three year secondary level exam were eligible to conduct some form of tertiary level education. To the extent that some individuals were still excluded because of insufficient qualifications, we assume that this will be controlled for by observed attributes in the empirical model.

The data in this study stems from various population registers administered by Statistics Sweden. It contains panel micro level data of all individuals registered as Swedish residents. Annual earnings are available 1982-2010 and from 1990 there is also yearly data on a richer set of individual background characteristics, including family situation and information on transfers related to social insurance systems and retirement pensions. Information on course registrations and completions in higher education are available from 1977. These records are very reliable as the distribution of resources to higher education in large part is determined by the numbers registered and completion of course credits ${ }^{5}$. There were about 256,000 individuals registered in higher education in 1992-1993, and about ten percent among them were born 1937-1950. Our study is restricted to a subset of these individuals. First, all individuals are conditioned to have a three year upper secondary education as their highest attained level of schooling ${ }^{6}$. Second, individuals are defined as treated if they registered in higher education for the first time in 1992 or 1993. Thus, importantly, we simplify the interpretation of AE enrollment by excluding all individuals registered in tertiary education 1979-19917. We also exclude individuals who immigrated to Sweden after age seven, to make it likely that individuals have gone through the same educational system. The remaining sample consists of 159,760 individuals, of which 4,558 were treated. The large number of untreated is advantageous for the process of finding appropriate comparisons. 
Table 1 presents sample means of selected covariates for treated and untreated and separately for males and females. About two thirds of the treated were females, which is in line with what has been observed for secondary education for adults (e.g. Stenberg et al. 2012). Enrollees are on average younger than the non-treated, with the gap in average age just above one year for both males and females. The means of incidence of social benefits and labor market programs indicate important differences between males and females regarding selectivity into education. The amount of completed higher education among treated was on average .77 years for males and 1.16 for females.

Figure 1 displays earnings trajectories 1982-2010 and retirement pension incomes received 1990-2010 for treated and untreated. The level of earnings in the 1980s is markedly lower among treated, which could contrast to the traditional view on selection in to education based on ability. While earnings are powerful controls for labor market productivity, earnings of females may be a less adequate measure due to family responsibilities. We therefore also construct a complementary measure of inherent productivity via a variable which reveals the highest earnings rank 1982-1990, conditional on age $^{8}$. Between 1990 and 1993, unemployment rates in Sweden soared from 2 to 11 percent. This is visible in the slight drop in earnings among untreated, but the drop is more pronounced among treated. This is expected since, at the time of enrollment, some factor has presumably changed to make the expected net present value of $\mathrm{AE}$ positive. The obvious example of such a change is job-loss, which decreases the opportunity costs, but many other examples are given in the literature?

There is no consensus in the applied economics literature on how to identify the point in time for the transition from work to retirement (Denton and Spencer 2009). Our baseline definition is that retirement occurs in the year when we first observe that an individual's received retirement pensions $\left(p_{i t}\right)$ exceed labor earnings $\left(e_{i t}\right)$. This means that an individual is defined as remaining on the labor market as long as $p_{i t}<e_{i t}$ but is retired in the first year we observe $p_{i t} \geq e_{i t}$ (alternative definitions are discussed in the empirical section). Figure 2 displays the Kaplan Meier survival rates in the labor force of treated and untreated from 1994 until 2010. In the raw data, the survival rates of the treated remain significantly higher throughout this period. This could of course reflect differences in characteristics, e.g. the age of the respective samples.

To interpret the survival rates by calendar year, one must keep in mind that most of the variation in retirement occurs around ages 61-66. It means that for the older half of our sample, born 1937-1944, differences would primarily arise in the middle of our observation window, while in the last few years virtually everyone is retired (with the 1944 cohort in 2010 aged 66). For our younger half, born 1944-1950, there are modest proportions of retirees up and until roughly 2004 when the cohort born 1944 turns 60 . Thus, there are overall only small treated-untreated differences prior to 2000 and the observed differences thereafter are generated by different age-segments of the sample.

To facilitate interpretation, Figure 3 displays the Kaplan Meier survival rates of our samples by age (44-68, numbers remaining at older ages is very small). The share of retired increases between age 64 and 68 from about 30 percent to more than 90 percent. Note that only our youngest cohort born 1950 is observed at age 44 (in 1994), for every age increment, an older cohort is added to increase the number of observations. The total sample is observed for ages 57-60 as our oldest 
Table 1 Descriptive averages of treated and untreated as measured in 1990, unless stated otherwise

\begin{tabular}{|c|c|c|c|c|c|c|c|c|c|c|}
\hline & \multicolumn{5}{|c|}{ Males } & \multicolumn{5}{|c|}{ Females } \\
\hline & $\mathrm{AE}$ & No $A E$ & $p$-value ${ }^{\text {a) }}$ & Matched comparisons & $p$-value ${ }^{a)}$ & $\mathrm{AE}$ & No $A E$ & $p$-value ${ }^{a)}$ & Matched comparisons & $p$-value ${ }^{\text {a) }}$ \\
\hline Age in $1992^{b)}$ & 46.56 & 47.85 & .000 & 46.65 & .495 & 46.07 & 47.17 & .000 & 46.07 & .982 \\
\hline Born 1937 & .022 & .046 & .000 & .028 & .340 & .013 & .034 & .000 & .014 & .581 \\
\hline Born 1950 & .105 & .071 & .000 & .107 & .904 & .139 & .099 & .000 & .142 & .770 \\
\hline No. of children at home & 1.411 & 1.286 & .000 & 1.437 & .551 & 1.488 & 1.290 & .000 & 1.488 & .981 \\
\hline Married & .684 & .742 & .000 & .676 & .632 & .716 & .698 & .033 & .708 & .520 \\
\hline Divorced & .120 & .114 & .510 & .111 & .485 & .169 & .161 & .272 & .165 & .734 \\
\hline Humanities track & .013 & .013 & .980 & .012 & .737 & .033 & .097 & .000 & .032 & .887 \\
\hline Business track & .046 & .089 & .000 & .046 & .999 & .079 & .383 & .000 & .086 & .289 \\
\hline Engineering track & .265 & .437 & .000 & .252 & .420 & .022 & .045 & .000 & .020 & .595 \\
\hline Professional track & .158 & .366 & .000 & .169 & .421 & .369 & .210 & .000 & .352 & .162 \\
\hline Inland of Norrland c) & .069 & .046 & .000 & .068 & .883 & .076 & .032 & .000 & .077 & .887 \\
\hline Stockholm county c) & .131 & .227 & .000 & .126 & .697 & .134 & .277 & .000 & .137 & .711 \\
\hline Foreign born & .019 & .018 & .668 & .017 & .576 & .013 & .019 & .010 & .012 & .909 \\
\hline Regional employment & .822 & .829 & .000 & .822 & .975 & .825 & .832 & .000 & .825 & .399 \\
\hline Farming and mining & .027 & .020 & .071 & .026 & .908 & .016 & .014 & .370 & .013 & .240 \\
\hline Construction & .079 & .130 & .000 & .073 & .527 & .012 & .023 & .000 & .015 & .326 \\
\hline Manufacturing & .271 & .299 & .023 & .267 & .801 & .076 & .144 & .000 & .071 & .467 \\
\hline Finance, insurance & .113 & .157 & .000 & .114 & .953 & .081 & .204 & .000 & .084 & .712 \\
\hline Public sector & .228 & .105 & .000 & .242 & .380 & .579 & .289 & .000 & .589 & .441 \\
\hline Earnings 1990 & 227.6 & 289.1 & .000 & 227.8 & .954 & 158.8 & 182.9 & .000 & 156.5 & .219 \\
\hline Earnings 1982 & 196.9 & 236.9 & .000 & 197.6 & .849 & 106.0 & 124.9 & .305 & 106.4 & .832 \\
\hline Earnings change 1990-1988 & -3.6 & 3.4 & .003 & -3.6 & .317 & 14.1 & 18.6 & .000 & 13.1 & .525 \\
\hline
\end{tabular}


Table 1 Descriptive averages of treated and untreated as measured in 1990, unless stated otherwise (Continued)

\begin{tabular}{|c|c|c|c|c|c|c|c|c|c|c|}
\hline Highest earnings rank 1982-1990 & - & - & & - & & .503 & .635 & .000 & .504 & .965 \\
\hline Unemp. insurance $(U I)>0$ & .046 & .016 & .000 & .038 & .267 & .072 & .040 & .000 & .070 & .767 \\
\hline average amount if $>0$ & 31.0 & 35.0 & .294 & 31.5 & .441 & 22.4 & 23.6 & .447 & 24.1 & .725 \\
\hline ALMP benefits $>0$ & .058 & .009 & .000 & .052 & .463 & .045 & .023 & .000 & .047 & .671 \\
\hline average amount if $>0$ & 18.6 & 22.2 & .274 & 24.3 & .557 & 28.6 & 26.2 & .330 & 28.5 & .782 \\
\hline Parental leave benefits $>0$ & .029 & .014 & .000 & .026 & .650 & .024 & .018 & .019 & .021 & .440 \\
\hline average amount if $>0$ & 11.9 & 11.4 & .852 & 15.7 & .658 & 23.4 & 29.5 & .147 & 20.3 & .315 \\
\hline Sick-leave benefits $>0$ & .655 & .584 & .000 & .664 & .638 & .773 & .716 & .000 & .770 & .763 \\
\hline average amount if $>0$ & 17.3 & 9.8 & .000 & 16.6 & .787 & 9.7 & 9.0 & .058 & 10.0 & .745 \\
\hline Social welfare benefits $>0$ & .042 & .017 & .000 & .033 & .239 & .038 & .021 & .000 & .038 & .999 \\
\hline average amount if $>0$ & 9.6 & 6.1 & .009 & 8.9 & .401 & 5.3 & 5.3 & .930 & 6.0 & .635 \\
\hline At some point registered in $\mathrm{HE}$ & 1.000 & .018 & .000 & .028 & .000 & 1.000 & .041 & .000 & .052 & .000 \\
\hline Completed HE on average & .773 & .009 & .000 & .020 & .000 & 1.165 & .025 & .000 & .036 & .000 \\
\hline Fraction completed less than 1 year & .503 & .011 & .000 & .013 & .000 & .391 & .023 & .000 & .029 & .000 \\
\hline Fraction completed $1-2$ years & .233 & .005 & .000 & .010 & .000 & .146 & .012 & .000 & .015 & .000 \\
\hline Fraction completed $2-3$ years & .119 & .001 & .000 & .003 & .000 & .307 & .002 & .000 & .004 & .000 \\
\hline Fraction completed 3 years or more & .145 & .001 & .000 & .002 & .000 & .156 & .004 & .000 & .004 & .000 \\
\hline $\mathrm{N}$ & 1,445 & 113,183 & & 1,445 & & 3,113 & 42,019 & & 3,113 & \\
\hline
\end{tabular}

Amounts given in thousands of SEK (2004 prices), $€ 100$ was app. SEK 970 .

a) $t$-test for equality between average of treated and untreated matched comparisons.

b) Balancing tests also include age dummies (14 categories), dummies for number of children (six categories), age of children (six categories) and annual earnings each year 1982-1990.

c) The inland of Norrland is a sparsely populated area in the north of Sweden with permanently higher than average unemployment rates. Stockholm County hosts 20 percent of the population, and the overall employment level is higher than in any other region of Sweden. 


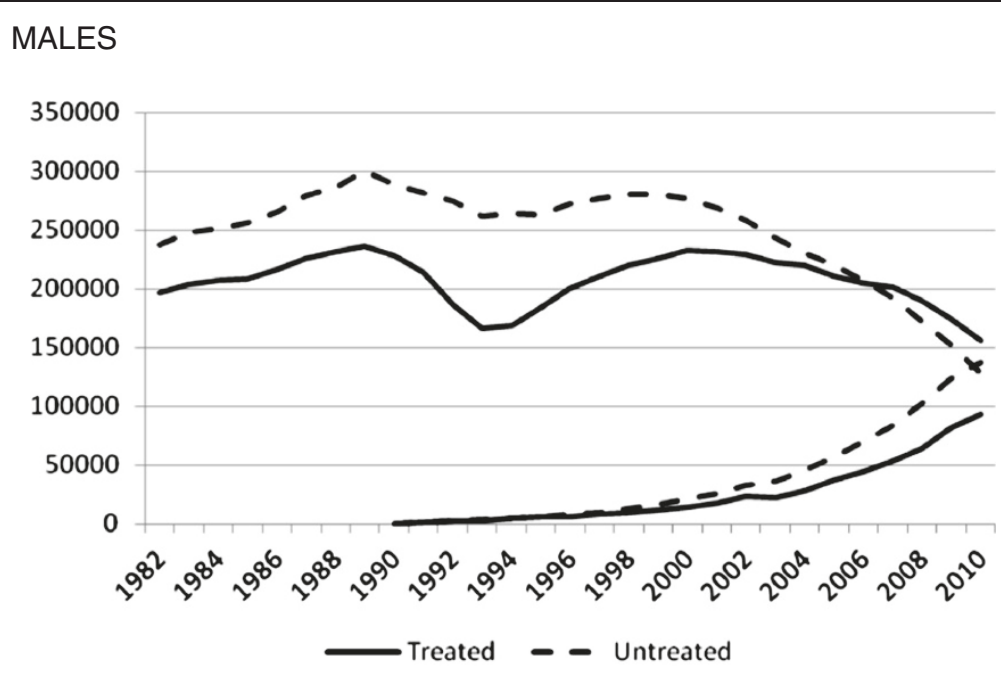

\section{FEMALES}

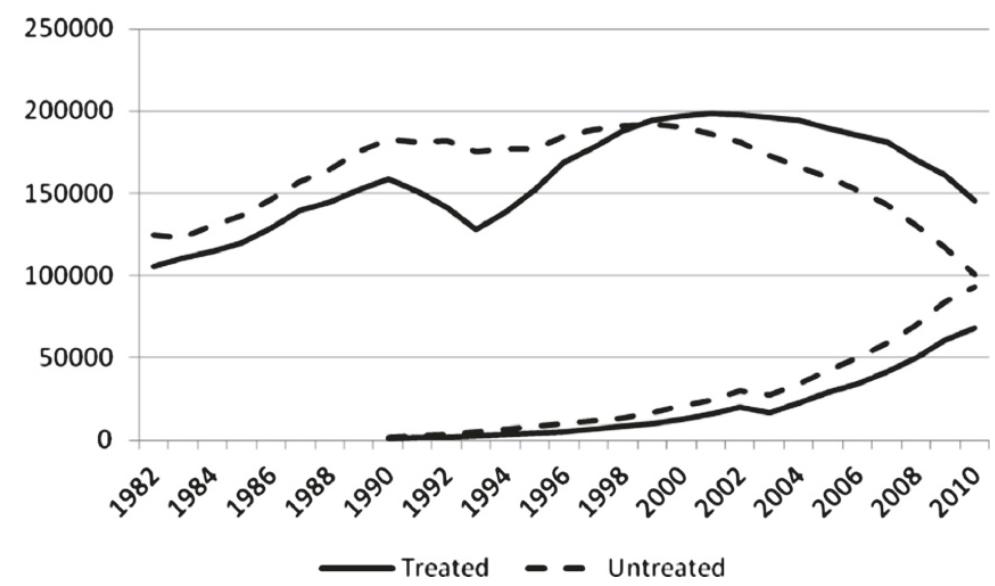

Figure 1 Descriptive statistics, trajectories of earnings 1982-2010 and retirement pension incomes 1990-2010.

cohort (born 1937) is observed for the first time aged 57 (in 1994), and our youngest cohort (born 1950) is observed for the last time aged 60 (in 2010). Subsequently, for each age category above 60 , the youngest cohort drops out and at age 73 only our oldest cohort (born 1937) remains.

Figure 4 shows the differences between the age-related survival rates, and 95 percent confidence intervals. At ages 61-66, the proportions remaining on the labor market is on average higher among treated males and females, by 5.2 and 5.8 percentage points respectively. This implies that the difference observed in Figure 2 cannot be explained by age alone. There is no officially stated retirement age in Sweden. Older employees are covered by the general employment protection legislation until aged 67. The threshold was increased from 65 to 67 in 2003 but it was only gradually implemented as it could be overruled by existing collective agreements signed before 2003. In our sample, the proportion still active at age 65 is about 3 percentage points higher in 2010 than in $2005^{10}$. 


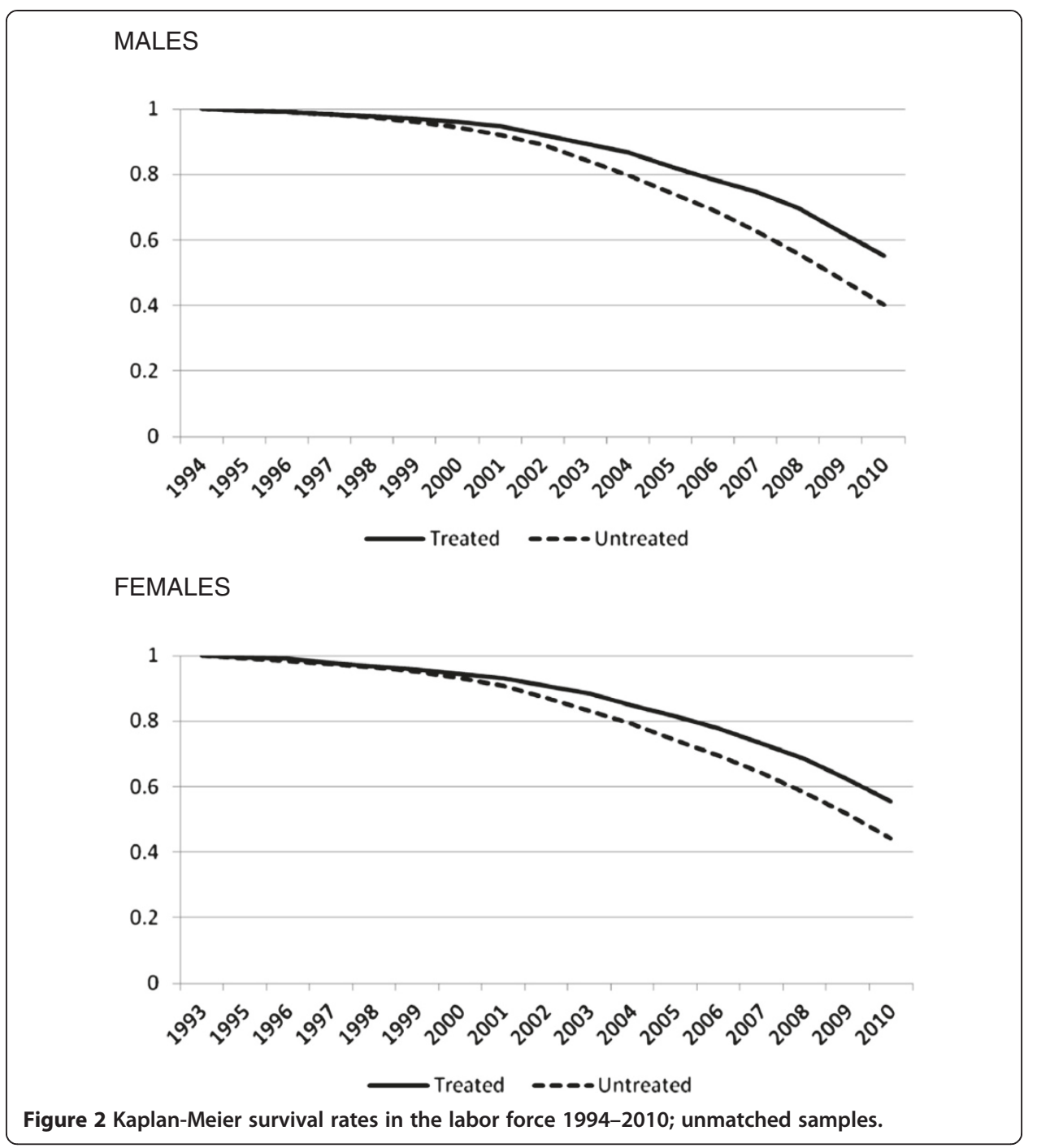

\section{Empirical strategy}

To identify the impact of $\mathrm{AE}$ on retirement decisions, we employ propensity score matching adapted for duration outcomes as in de Luna and Johansson (2010) and Fredriksson and Johansson (2008). Thus, treated individuals are matched with a comparison group obtained by nearest-neighbor matching on the propensity score (e.g. Rosenbaum and Rubin 1983, Smith and Todd 2005). In a second step, we compare the timing of retirement of treated and matched comparisons by non-parametric estimation of survival in the labor force. The propensity score is obtained from Probit model estimates of the probability of being treated. For each given participant in AE, the untreated individual with the "nearest" propensity score is selected as the matched comparison. We use one-to-one matching as our baseline, also employing four to one matching as a robustness check with improved precision but at the risk of generating bias. The applied method provides a relevant estimate of the average treatment effect on the treated $(A T T)$ even if there is heterogeneity in treatment effects.

For a causal interpretation of our estimates, the main assumptions necessary are: $i$ ) the estimated probability of enrollment is strictly positive and strictly below one; ii) 


\section{MALES}

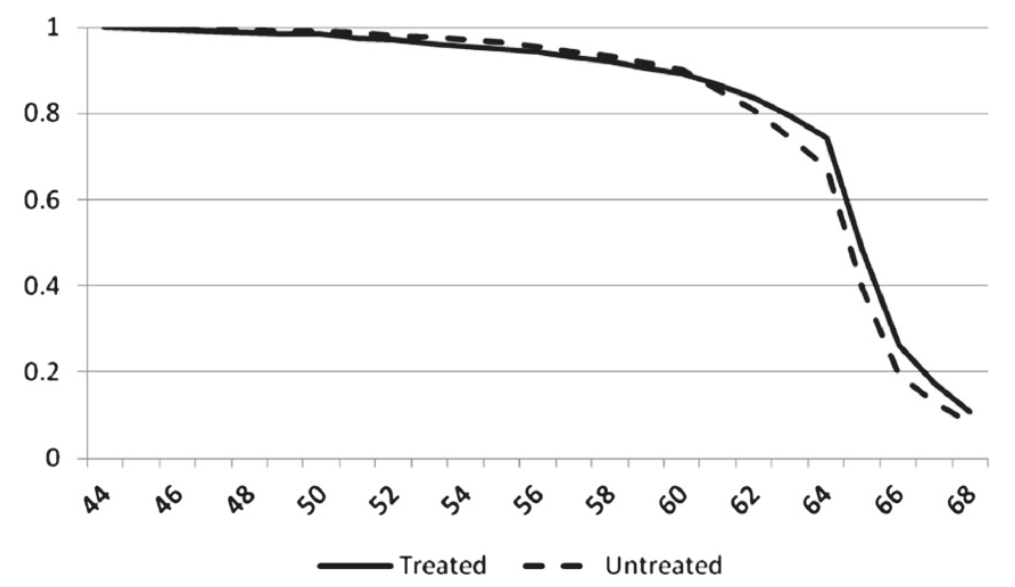

FEMALES

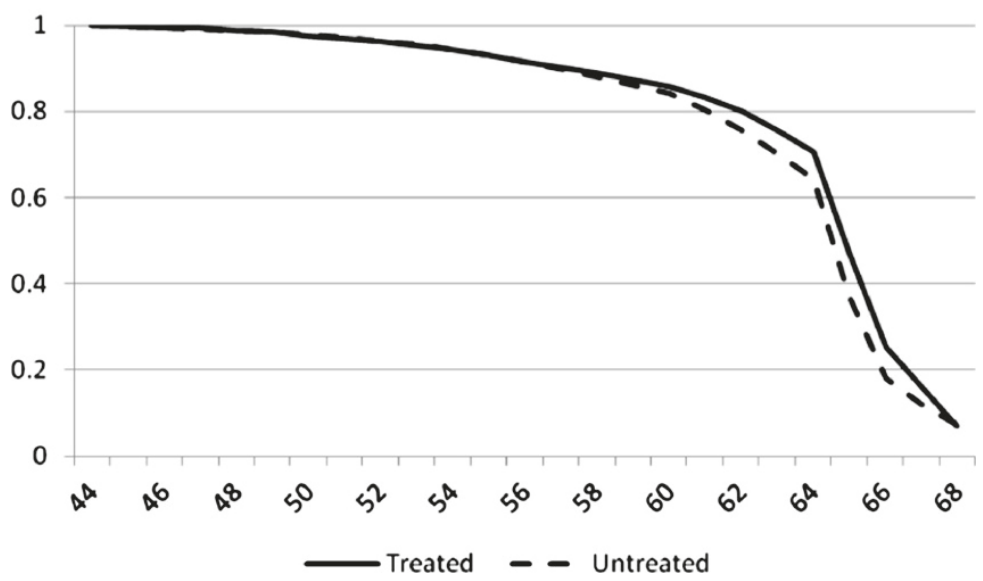

Figure 3 Kaplan-Meier survival rates by age; unmatched samples.

enrollees must not influence the outcomes of other individuals in the study (the stable unit treatment value assumption, SUTVA, or no interference assumption); iii) conditional on our covariates, unobservable attributes affecting AE enrollment are independent of the outcome variable. This last "unconfoundedness assumption" is crucial as our estimation technique is based on selection on observables. With non experimental data, it is not possible to rule out that treated and their matched comparisons systematically differ in some unobserved aspect which affects decisions on both enrollment and on retirement. For some guidance on this matter, several empirical studies have assessed non experimental estimators (Heckman and Smith 1999, Table 7, Heckman et al. 1999 ch 10, Smith and Todd 2005, Diaz and Handa 2006). These studies have had access to a treatment effect estimate based on experimental evidence. This is used as a benchmark and compared with results from "robustness checks" where the randomized control group has been substituted with a conventional non-experimental data set. The results indicate that bias is modest in estimators based on non-experimental data, but only as long as data is of high quality. Considering that our register data is unusually rich and accurate, free from measurement errors due to recall errors, rounding errors 


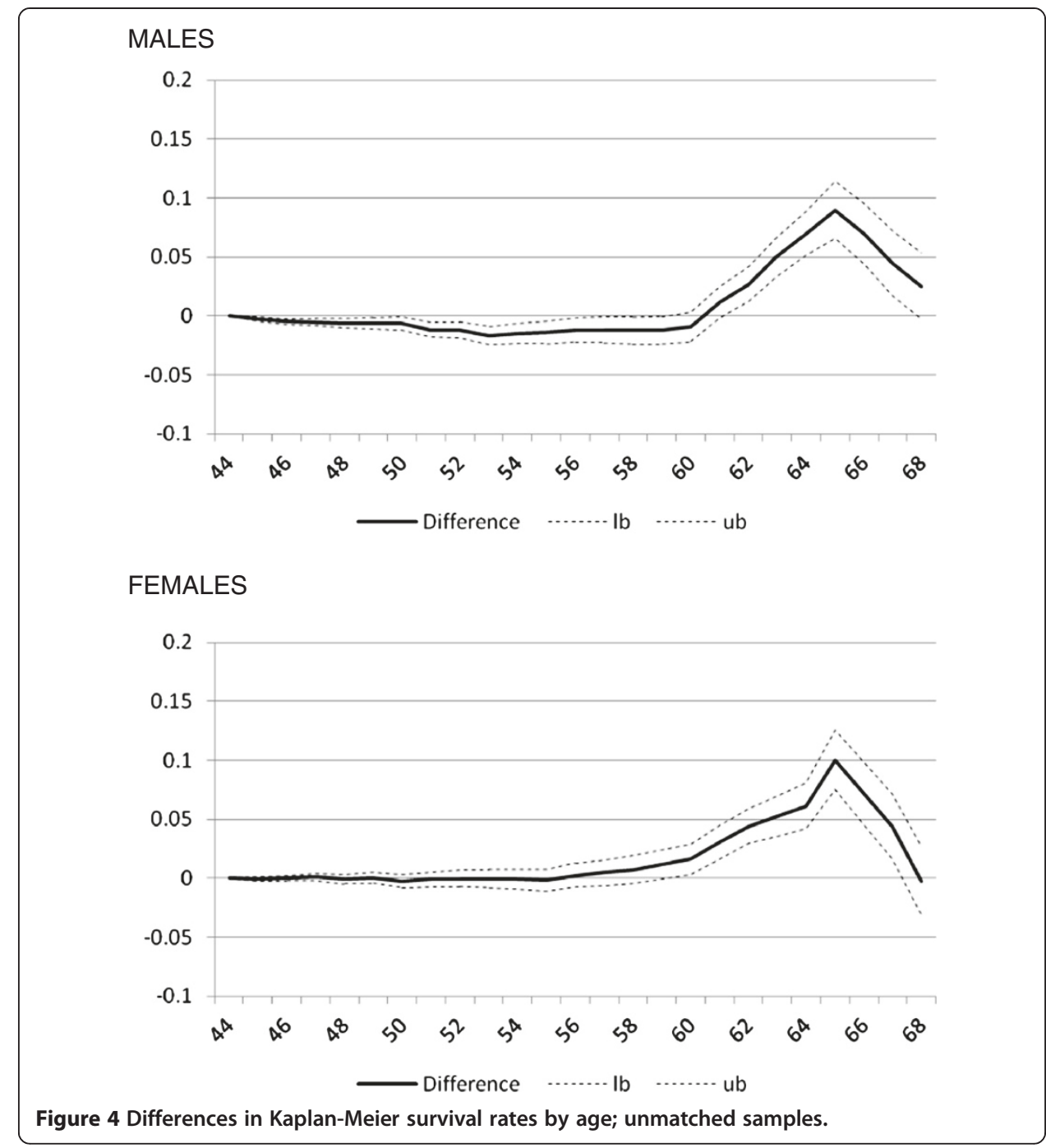

and/or top-coding, the credibility of our approach is supported by the existing empirical evidence ${ }^{11}$.

Table 2 provides selected coefficient estimates from Probit regressions for the probability of treatment. The coefficients are informative in terms of answering the question "who enrolls", but the primary purpose is to provide us with fitted values of the individual's propensity to enroll, which is at the basis of the ensuing matching procedure ${ }^{12}$. Balancing tests for the samples of males and females are presented in Table 1 (selected variables). In all, there are no unbalanced variables, i.e. the samples of treated and their matched comparisons display no significant differences in average characteristics. In total, we check the balance between treated and the untreated comparison groups with regard to educational track completed at three year upper secondary level (5 categories), employment sector (7 categories), age (14 categories), number of children at home (6), age of children (6), rural or metropolitan area (3), regional employment rate, five different kinds of social insurance benefits related to unemployment insurance (UI), parental leave, sick-leave, early retirement pensions and social welfare, applying both dummy variables (incidence of the various benefits) and continuous measures of 
Table 2 Probit model maximum likelihood estimation of the propensity score, variables measured in 1990, unless stated otherwise

Dependent variable: binary indicator variable of registration in higher education 1992-1993.

\begin{tabular}{|c|c|c|c|c|c|c|}
\hline \multirow[b]{3}{*}{ Humanities track } & \multicolumn{3}{|c|}{ Males } & \multicolumn{3}{|c|}{ Females } \\
\hline & \multicolumn{2}{|c|}{ Coefficient } & \multirow{2}{*}{$\begin{array}{c}\text { Std.Err. } \\
(.107)\end{array}$} & \multicolumn{2}{|c|}{ Coefficient } & \multirow{2}{*}{$\begin{array}{c}\text { Std.Err. } \\
(.046)\end{array}$} \\
\hline & -.733 & $* * *$ & & -.794 & ${ }^{* * *}$ & \\
\hline Business track & -.938 & $* * *$ & $(.049)$ & -1.268 & ${ }^{* * *}$ & $(.084)$ \\
\hline Engineering track & -.830 & $* * *$ & $(.029)$ & -.603 & ${ }^{* * *}$ & $(.058)$ \\
\hline Professional track & -1.121 & $* * *$ & $(.031)$ & .060 & & $(.040)$ \\
\hline Construction & -.093 & & $(.064)$ & & & \\
\hline Manufacturing & .020 & & $(.056)$ & -.181 & $* * *$ & $(.058)$ \\
\hline Finance, insurance & -.126 & ${ }^{* *}$ & $(.061)$ & -.150 & ${ }^{* * *}$ & $(.054)$ \\
\hline Public sector & .289 & $* * *$ & $(.057)$ & .429 & $* * *$ & $(.047)$ \\
\hline Earnings $1990^{\text {a) }}$ & -.087 & $* * *$ & $(.015)$ & -.166 & $* * *$ & $(.030)$ \\
\hline Highest earnings rank 1982-1990 & & & & .073 & ${ }^{* * *}$ & $(.024)$ \\
\hline ALMP benefits $>0$ & .391 & $* * *$ & $(.068)$ & .375 & ${ }^{* * *}$ & $(.093)$ \\
\hline - amount if above zero ${ }^{\text {a) }}$ & & & & -.799 & $* * *$ & $(.246)$ \\
\hline \multicolumn{7}{|l|}{ Parental leave benefits $>0$} \\
\hline - amount if above zero a) & .092 & & $(.333)$ & -.307 & * & $(.178)$ \\
\hline Sick-leave benefits $>0$ & .056 & ${ }^{* *}$ & $(.025)$ & .116 & ${ }^{* * *}$ & $(.026)$ \\
\hline - amount if above zero ${ }^{\text {a) }}$ & .255 & $* * *$ & $(.057)$ & & & \\
\hline Social welfare benefits $>0$ & & & & .139 & ${ }^{* *}$ & $(.059)$ \\
\hline \multicolumn{7}{|l|}{ - amount if above zero ${ }^{a)}$} \\
\hline - amount if above zero ${ }^{\text {a) }}$ & -.081 & & $(.217)$ & & & \\
\hline Regional employment $1991^{\text {b) }}$ & -2.884 & $* * *$ & $(.551)$ & & & \\
\hline Inland of Norrland 1991 & & & & .313 & ${ }^{* * *}$ & $(.043)$ \\
\hline Stockholm county 1991 & -.199 & $* * *$ & $(.039)$ & -.338 & $* * *$ & $(.058)$ \\
\hline Married & -.013 & & $(.035)$ & .096 & ${ }^{* * *}$ & $(.032)$ \\
\hline Divorced & .012 & & $(.043)$ & .111 & ${ }^{* * *}$ & $(.038)$ \\
\hline Foreign born & .018 & & $(.082)$ & -.140 & * & $(.084)$ \\
\hline One child at home & .026 & & $(.034)$ & & & \\
\hline Two children at home & .057 & ${ }^{*}$ & $(.035)$ & -.081 & ${ }^{* * *}$ & $(.029)$ \\
\hline Three children at home & .159 & $* * *$ & $(.044)$ & -.057 & & $(.043)$ \\
\hline Four children at home & .049 & & $(.085)$ & & & \\
\hline Five children or more at home & .317 & ${ }^{* *}$ & (.134) & & & \\
\hline Child home aged 0-3 & .035 & & $(.046)$ & & & \\
\hline Child home aged 4-6 & -.080 & ${ }^{*}$ & $(.042)$ & .051 & & $(.045)$ \\
\hline Children aged 7-10 & & & & .094 & $* * *$ & $(.031)$ \\
\hline Children aged 11-15 & & & & .135 & $* * *$ & $(.026)$ \\
\hline Children aged 16-17 & & & & .076 & $* * *$ & $(.026)$ \\
\hline Children aged 18 or over & & & & .141 & $* * *$ & $(.024)$ \\
\hline Pseudo $R^{2}$ & .154 & & & .163 & & \\
\hline
\end{tabular}

Notes: ${ }^{* * *}$ significant at the $1 \%$ level. ${ }^{* *}$ at the $5 \%$ level. ${ }^{*}$ at the $10 \%$ level.

a) SEK 2004 prices divided by 100,000, $€ 100$ was approximately SEK 970.

b) Regressions include age dummies and in the case of males an interaction term between Humanities tracking and two children at home. For females, also included are the following interactions: business track interacted with earnings 1990 , 1987, two children at home, manufacturing, incidence of ALMP benefits, amount of ALMP benefit. Professional track interacted with "other" sector, earnings 1982, incidence of ALMP benefits, amount of ALMP benefit. Stockholm interacted with incidence of sick-leave benefits. 
amounts in SEK in 1990. We also control for and obtain balanced samples on pretreatment annual earnings levels and earnings trajectories (changes) 1982 - 1990.

The main threat to our identification strategy is that unobserved ability (or productivity) is correlated with the enrollment decisions. If ability also influences future decisions on the timing of retirement, we risk confounding the impact of education with unobservable individual attributes. Our controls for ability include information on annual earnings, which are matched between treated and matched comparisons 1982-1990. Adding information on transfers related to both unemployment, family characteristics and labor market marginalization, we believe our identification strategy appears reasonable, not least in view of that several of the above mentioned studies have emphasized the importance of earnings as a powerful control for self-selection into training programs ${ }^{13}$.

Issues which may still remain include differences in individuals' "taste" for education, preferences for leisure and differences in time horizons (Hairault et al. 2010, Magnac et al. 2013). Even if individuals are identical in terms of expected yearly returns and costs of education, different time horizons (or taste for education) may produce different enrollment decisions. In the present case, the sample is conditioned to have the same completed years of schooling, and no prior participation in formal AE earlier in life, which decreases heterogeneity of samples. Our empirical framework also means that confounders which could bias our results are limited to those remaining after conditioning on our rich set of covariates. As a further check if such confounders remain, Section 4 contains robustness checks where we exclude individuals for whom there is least common support in data, i.e. observations in the tails of the propensity score distribution. As pointed out by Black and Smith (2004), selection bias due to unobservables is most severe in the tails of the distribution of the propensity score, given joint normality in the distribution of the error terms of regressions on the participation and the outcome. If a confounding factor drives the results, one would expect some attenuation in our estimates as the samples are narrowed down by 10, 20, 30, 40 and 50 percent. In short, we find little evidence of this ${ }^{14}$.

Concerning pre-enrollment dynamics, our matched samples are as expected different in terms of changes 1990-1991 in earnings and employment status prior to AE enrollment. The conventional view in the program evaluation literature has been that an earnings dip prior to enrollment reflects a temporary change. It is therefore excluded from the control variables as it would otherwise risk generating upward biased estimates (Ashenfelter 1978). In line with this convention, our Probit specification only includes information up and until 1990, i.e. it does not take into account changes occurring immediately prior to $\mathrm{AE}$ enrollment ${ }^{15}$. However, if a drop in pre-program earnings signals a shock with permanent effects, it is necessary to control for such changes. We assess the importance of these opposing hypotheses with robustness checks where relevant covariates reflecting changes 1990-1991 are included in our Probit specification. The balancing tests then include an additional 22 variables (details provided in Section 4).

\section{Results}

Figure 5 shows the Kaplan-Meier survival rates by age of treated and their untreated matched comparisons, using one-to-one matching. Figure 6 displays the differences between these survival rates, including 95 per cent confidence intervals for the point 


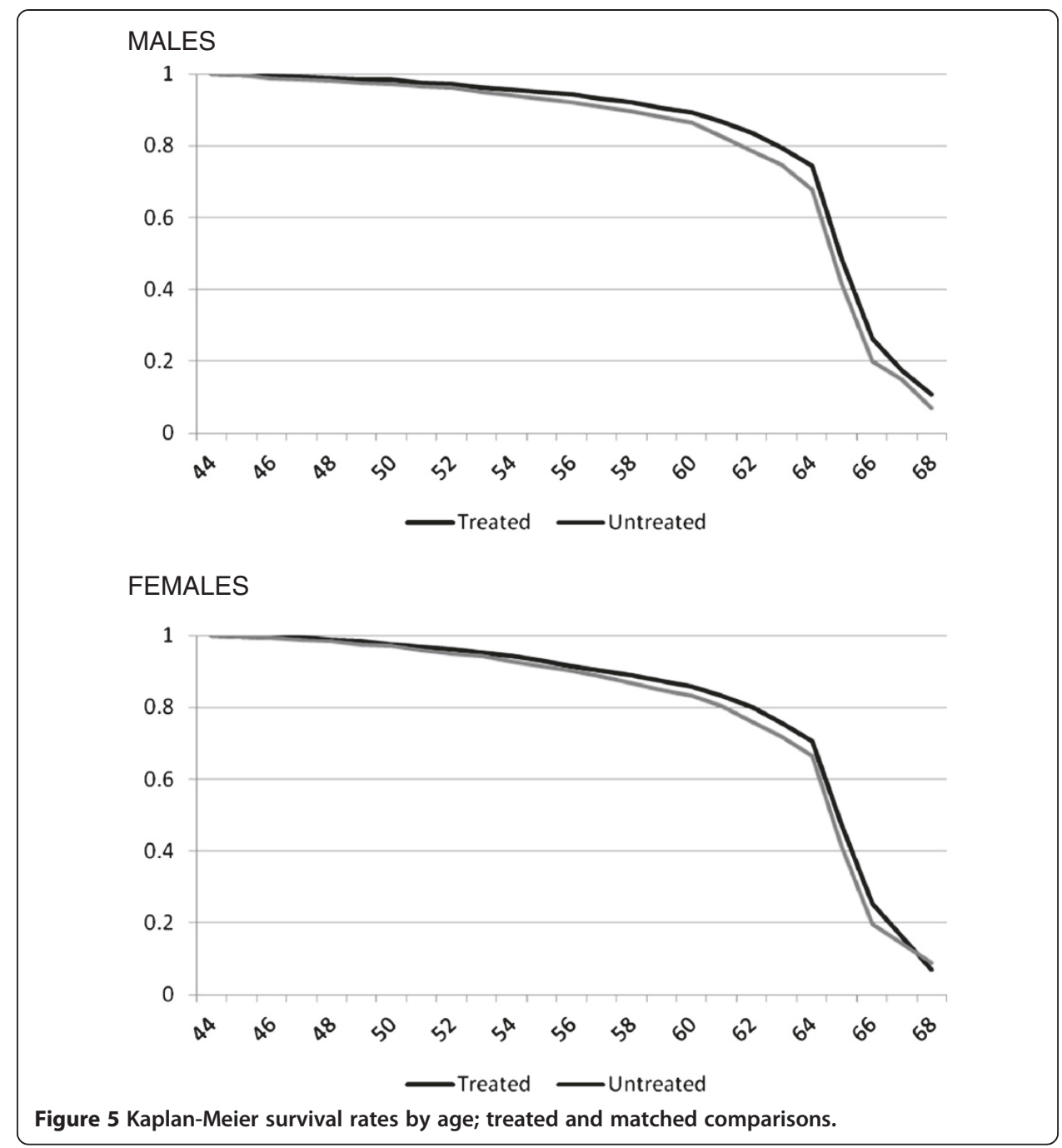

estimates. The results indicate higher labor market participation for treated males and females with log rank tests rejecting the hypothesis of no differences. The test statistics are significant at a one percent level, supporting the hypothesis that higher education delays retirement ${ }^{16}$. The differences in survival rates are at ages 61-66 on average 5.6 percentage points for males and 4.5 for females. As an alternative, four-to-one -matching which in theory improves precision but increases bias, yields average differences of 4.5 percentage points for males and 4.0 for females, also significant at the one percent level.

To get an indication of whether our estimates reflect unobserved heterogeneity, we "trim" our samples by excluding treated individuals in the tails of the propensity score distributions where common support is the weakest. If unobservable confounders affect our results; the trimming procedure should yield systematic changes in the estimated results. An obvious drawback here is that trimming may also affect the results through heterogeneity in treatment effects. Table 3 contains results where the matching has been conditioned on trimming. The differences in survival rates remain relatively stable, and are statistically significant throughout. Importantly, there is little evidence that the trimming reduces the estimates, which could have been a sign of upward bias 


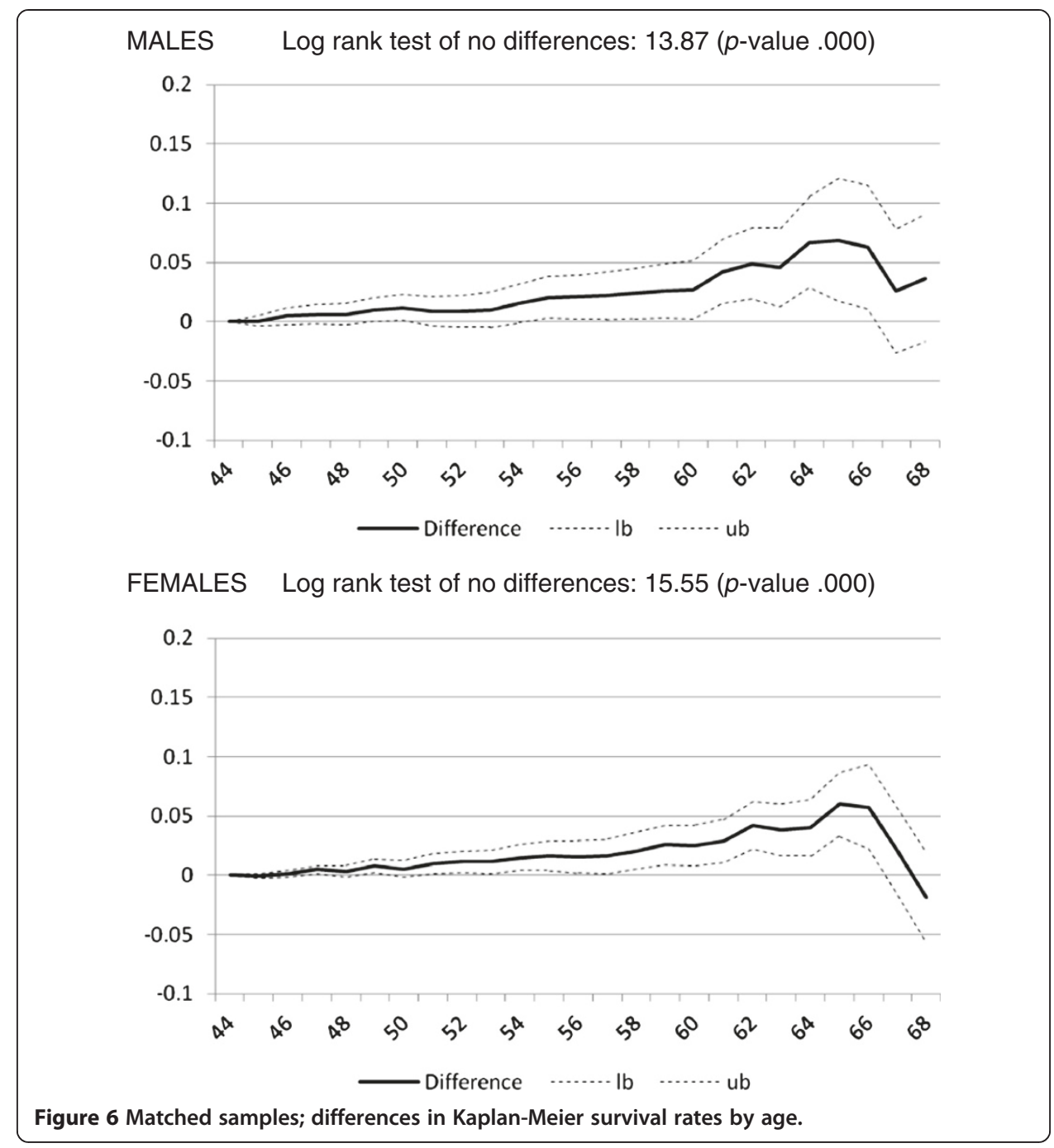

Table 3 Average differences in survival rates at different ages, $p$-values refer to log-rank tests of no differences

\begin{tabular}{|c|c|c|c|c|c|c|c|c|}
\hline & \multicolumn{4}{|c|}{ MALES } & \multicolumn{4}{|c|}{ FEMALES } \\
\hline & $49-54$ & $55-60$ & $61-66$ & $p$-value & $49-54$ & $55-60$ & $61-66$ & $p$-value \\
\hline Matching 1:1 & .011 & .023 & .056 & .000 & .010 & .020 & .045 & .000 \\
\hline Trim 10\% & .004 & .006 & .034 & .008 & .002 & .015 & .034 & .005 \\
\hline Trim 20\% & .001 & .003 & .035 & .010 & .003 & .015 & .035 & .005 \\
\hline Trim 30\% & -.001 & .002 & .036 & .014 & .005 & .015 & .047 & .000 \\
\hline Trim 40\% & .001 & .008 & .050 & .012 & .004 & .014 & .044 & .002 \\
\hline Trim 50\% & -.004 & .000 & .050 & .005 & .004 & .017 & .050 & .003 \\
\hline Matching 4:1 & .004 & .009 & .045 & .000 & .008 & .019 & .040 & .000 \\
\hline Trim 10\% & .005 & .013 & .047 & .000 & .006 & .015 & .034 & .000 \\
\hline Trim 20\% & .003 & .012 & .049 & .000 & .008 & .014 & .032 & .001 \\
\hline Trim 30\% & .001 & .011 & .050 & .000 & .006 & .011 & .032 & .003 \\
\hline Trim 40\% & .003 & .010 & .060 & .000 & .005 & .005 & .037 & .002 \\
\hline Trim 50\% & .004 & .009 & .055 & .000 & .005 & .003 & .039 & .000 \\
\hline
\end{tabular}


due to unobserved heterogeneity. If an unmeasured confounder still drives these results, it would have to be close to uniformly distributed in our samples or absent from the tails of the propensity score distribution.

Overall, treated-untreated differences partly arise before age 60, reflecting early retirement schemes which for the most part are health related. There is also an element of lay-offs where employers offer employees a deal which includes occupational pension schemes. For instance, following the IT crisis in 2000-2001, the fractions receiving such pensions increased by more than 50 percent among individuals aged 60-61 at the time. However, these arrangements concerned fractions which represented less than one third of those with early retirement pensions ${ }^{17}$.

As discussed in Section 3, even if an empirical model successfully controls for differences in individuals time invariant characteristics, it may be that dynamic factors explain educational enrollment and later retirement decisions. Extending our matching model and the balancing tests to include earnings drops and other changes 1990-1991 in transfers and employment status has modest effects on the estimates, increasing the differences in survival rates at ages 61-66 by less than one percentage point (as considered across the board $)^{18}$. The estimates are displayed in Table 4 .

As for unobserved dynamic factors, some individuals may enroll education following decisions to search for jobs, i.e. either to change jobs or increase the number of hours worked. The concern is that treated enrollees who search for jobs are partly matched with comparisons not searching for jobs (Heckman and Smith 1999). Potential effects of job search, e.g. through mobility, could then hypothetically also influence decisions on the timing of retirement and generate biased estimates. If job-search decisions confound our estimates, and if the ability to search is correlated with productivity, we would expect some job-searchers to drop-out of education following that they find a

Table 4 Extended specification of matching model

\begin{tabular}{|c|c|c|c|c|c|c|c|c|}
\hline & \multicolumn{4}{|c|}{ MALES } & \multicolumn{4}{|c|}{ FEMALES } \\
\hline & $49-54$ & $55-60$ & $61-66$ & $p$-value & $49-54$ & $55-60$ & $61-66$ & $p$-value \\
\hline Matching 1:1 & .017 & .035 & .069 & .000 & .012 & .029 & .060 & .000 \\
\hline Trim 10\% & .007 & .023 & .041 & .016 & .011 & .028 & .050 & .000 \\
\hline Trim 20\% & .008 & .017 & .032 & .032 & .009 & .022 & .046 & .000 \\
\hline Trim 30\% & .006 & .004 & .053 & .001 & .006 & .011 & .037 & .004 \\
\hline Trim 40\% & .009 & .029 & .074 & .000 & .007 & .021 & .040 & .004 \\
\hline Trim 50\% & .001 & .008 & .046 & .017 & .011 & .022 & .042 & .005 \\
\hline Matching 4:1 & .009 & .016 & .047 & .000 & .008 & .018 & .045 & .000 \\
\hline Trim 10\% & .008 & .024 & .057 & .000 & .009 & .024 & .053 & .000 \\
\hline Trim 20\% & .004 & .018 & .054 & .000 & .009 & .021 & .050 & .000 \\
\hline Trim 30\% & .003 & .020 & .065 & .000 & .008 & .015 & .047 & .000 \\
\hline Trim 40\% & .005 & .024 & .072 & .000 & .008 & .012 & .044 & .000 \\
\hline Trim 50\% & .006 & .022 & .066 & .000 & .007 & .006 & .038 & .002 \\
\hline
\end{tabular}

Average differences in survival rates at different ages, $p$-values refer to log-rank tests of no differences. Note: The extended model includes all variables of the baseline model but also balances treated and matched comparisons on nine possible transitions in labor force status 1990-1991, between employment, unemployment and outside the labor force (OLF). OLF is defined as annual earnings below SEK 20,000 (app. $\$ 3,000$ ) and no transfers related to unemployment insurance. Also included are indicator variables of newly married or divorced in 1991 and 1992 , changes in amounts of social insurance benefits 1990-1991 and 1991-1992. 
job, and thereby produce a spurious effect between treated with no completed education and the timing of retirement. Robustness checks indicate results consistent with the hypothesis that it is education, rather than job-search, which affects the timing of retirement. Treated individuals who did not complete any education are associated with very small and insignificant differences in estimated survival (log-rank test $p$-values .488 and .395). In contrast, treated individuals completing one year or more display significant differences at ages 61-66 amounting to about 6.7 percentage points for males and 5.6 for females ( $p$-values of .006 and .000).

To check if our results are sensitive to alternative definitions of retirement, we first extend the definition of labor market activity to also include unemployment insurance benefits, i.e. on top of annual earnings. The results remain very stable compared with the ones presented in Table 3, diverging by on average .3 percentage points at ages 6166. Second, in Figure 7, we consider part time retirement by defining exit from the labor market to occur as soon as pension incomes are above zero. Naturally, early retirement then becomes more frequent and only small fractions remain in the labor force when aged 66 . The point estimates of the treatment effect drops; for males to on

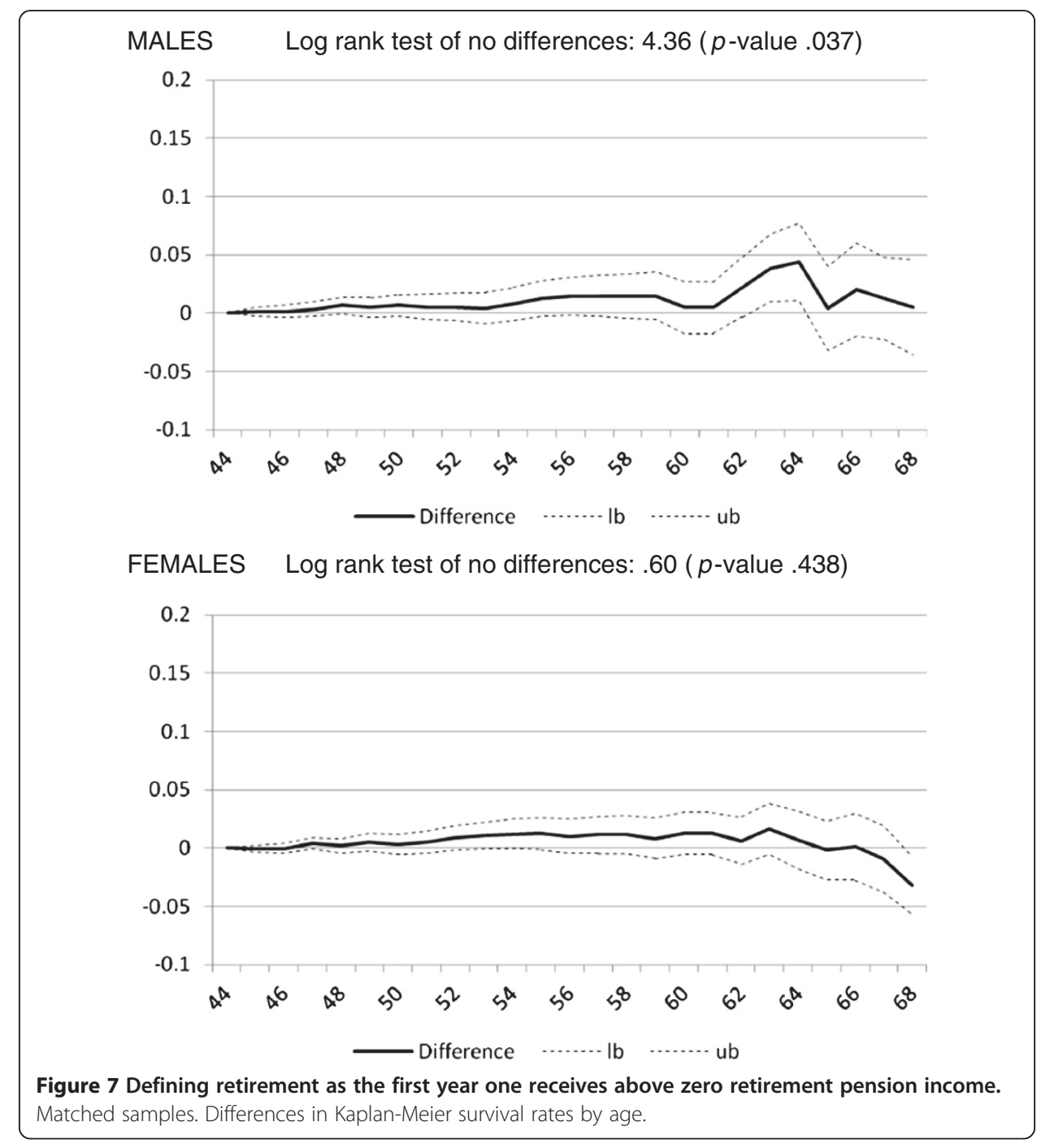


average 2.2 percent for the age interval 61-66. Estimates pertaining to females drop even further and are on average below one percent, with log-rank tests failing to reject the null of no differences between treated and untreated ${ }^{19}$. The result is partly driven by pension incomes which are substantially lower than labor earnings. If we employ the definition that retirement occurs when pension transfers exceed half of annual earnings, estimates again resemble the ones presented in Table 3, with average differences at ages 61-66 above 4 percent for both males and females and p-values below .05. In all, the estimates suggest that the positive effects for females exposed in Table 3 and in Figure 6 largely reflect differences in part-time retirement and/or part-time employment. Thus, while the timing of the first income from pensions is similar for treated and untreated females, treated remain in the labor force longer such that their earnings to a greater extent exceed the retirement pension payments.

Finally, we tentatively seek to assess the impact of delayed retirement in terms of annual earnings. Figure 8 presents the average annual earnings and annual retirement pension payments when aged 59-68, for the treated samples and their matched comparisons. One may first of all note that the percentage earnings differences between

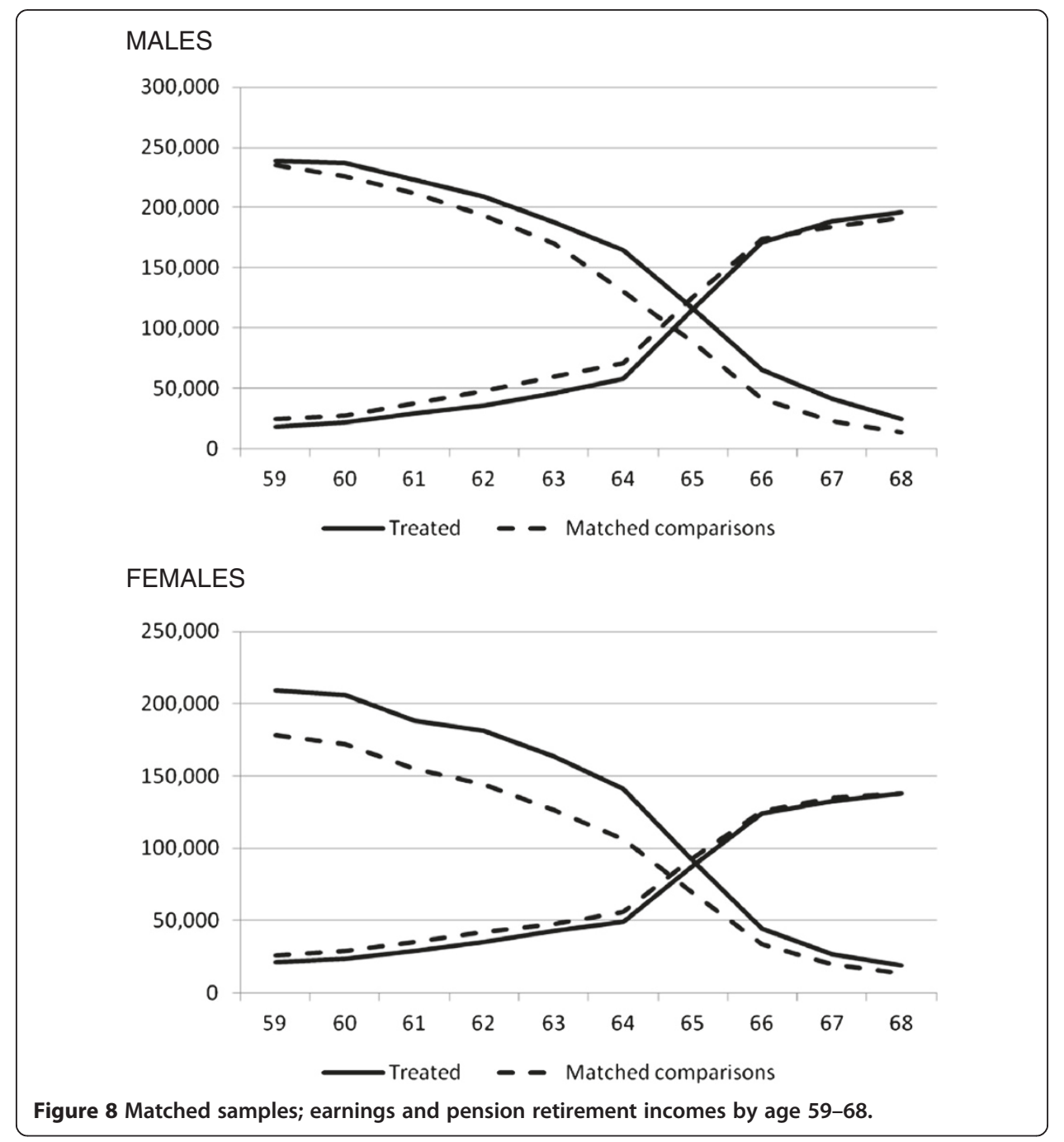


treated and matched comparisons increase as the overall average earnings levels decrease with age (though not always in absolute terms, but at age 64 the treateduntreated difference represents about 30 percent for both males and females). Ideally, one would like to distinguish the earnings effect related to delaying retirement from the conventional earnings premium of education. While we fully acknowledge the difficulties of such a task, one may at least get a rudimentary idea if one uses a benchmark of the conventional earnings premium and consider the payoff in excess of this benchmark as attributable to decisions on the timing of retirement. The returns to higher education for adults in Sweden are approximately 2-4 percent for males and 7-8 percent for females (Stenberg and Westerlund 2013). We therefore assume treated earnings exceeding untreated by 2-4 and 7-8 percent to be "normal", but any larger (or excess) differences we attribute to retirement decisions. The excess earnings differences in Figure 8 (from age 61 until age 67) sums up to non-trivial amounts. For males, these correspond to 51 percent of the average annual earnings at age 60, and for females to 62 percent $^{20}$. Expressed in terms of returns on annual earnings for individuals enrolling higher education at age 42, with a 25 year perspective (until aged 67), it would for males correspond to an additional .8 percentage points earnings returns per year of higher education over the 25 year period and 1.4 percentage points for females. However, we emphasize that these numbers are based on several untestable assumptions and should be interpreted with caution ${ }^{21}$.

\section{Conclusions}

Long term trends of improved health and increased longevity, combined with structural changes in the labor market, are likely to increase interest in higher education of mid-aged and older individuals. The scientific literature on the economic effects of such investments in human capital is limited, and the present study represents a first attempt to estimate effects on the length of working life, i. e. timing of retirement. Our main finding is that tertiary level education of individuals aged 42-55 has a potential for extending duration in the work force and postpone retirement. The magnitudes suggested by our estimates are large and, more generally, supports longstanding policy recommendations of the EU and the OECD to invest in education of adults. The quality of the data provides extensive controls for selectivity into education and the results are robust to alternative assumptions underlying the empirical model regarding potential influence of unobserved factors.

To extend the validity of our results, further studies from other economic contexts are required. Policy recommendations would also require a careful assessment of opportunity costs as short run costs of education for adults is substantial, not least due to foregone earnings. For this reason, it is perhaps symptomatic that proposals for adult education policies emerge from intergovernmental bodies (OECD and EU) whereas individual governments are more reluctant to stimulate measures which exert pressure on short run budget targets. This political problem may perhaps be relaxed by further research, but of course only if it provides supportive results. Finally, adult education encompasses important non-pecuniary aims, e.g. influencing democratic functions and public health, which need to be considered when designing the appropriate policy. 


\section{Endnotes}

${ }^{1}$ Hazan (2009) finds that lifetime labor supply does not increase with life expectancy. Incorporating the retirement decision into a Ben-Porath model (Ben-Porath 1967), the result questions the implication that investments in human capital should increase following an increase in expected labor supply (expected life expectancy).

${ }^{2}$ All else equal, human capital theory specify that the returns to educational investments decrease with age as there are fewer working years remaining to reap the potential rewards, and because of higher foregone earnings (Becker 1993). Option value models of investment in education assume continuously updated information where unexpected events such as economic fluctuations, changes in health, information or preferences, may provide incentives for adults to enrol formal education (e.g. Comay et al. 1973, Cameron and Heckman 2001, Heckman and Urzua 2008, Pissarides 2011).

${ }^{3}$ The gold standard in evaluation studies is random assignment, but one may note that studies based on high quality non-experimental data generally have been found to provide estimates which are cleared from most sources of systematic bias (Heckman and Smith 1999, Table 7, Heckman et al. 1999 ch 10, Smith and Todd 2005, Diaz and Handa 2006).

${ }^{4}$ On US data, see Autor et al. (2003)), Autor et al. (2008); on data from the UK and Europe; Goos and Manning (2007), Goos et al. (2009), Spitz-Oener (2006), Dustmann et al. (2009).

${ }^{5}$ Private educational institutes exist but like the public universities, they receive a fixed sum from the government per student when they register for a course and a roughly equal amount when students have completed the course.

${ }^{6}$ An alternative path to higher education existed for adults (above 25) with four years of work experience. Eligibility could then be achieved by completing passing grades in Swedish and English at a three year upper secondary level. However, these courses were typically completed at komvux which were not recorded in the official educational registries. Therefore, individuals who took this path are recorded with less than 12 years of schooling, and thus excluded from our analyses.

${ }^{7}$ To avoid conditioning on events occurring after enrollment, treated as well as untreated are allowed to register in higher education from 1994 and onwards. Our group of "untreated" will therefore on average complete small but positive amounts of higher education, but this has only a marginal impact on our estimates.

${ }^{8}$ This variable takes the value max $\left[\operatorname{rank}_{\mathrm{it}}\right]$ where $t$ is $1982,1983, \ldots$, , 1990. The rank in year $t$ is based on residual values $e_{i t}$ each year of the age adjusted regression: Earnings $s_{i t}$ $=a+b_{1}{ }^{*}$ age $e_{i t}+b_{2}{ }^{*}$ agesq $q_{i t}+e_{i t}$.

${ }^{9}$ For instance, changes in preferences, changes in borrowing constraints, new information (e.g. about working environments) and/or changes in relative wages which increase the expected earnings benefits of AE (Altonji 1993, Iwahashi 2007, Killingsworth 1982, Monks 1998, Wallace and Ihnen 1975, Warner and Pleeter 2001, Weiss 1971).

${ }^{10}$ Labor force participation and employment rates among 55-64 year olds are slightly higher in Sweden than the OECD average. See Eklöf and Hallberg $(2004,2010)$ and Karlström et al. (2004).

${ }^{11}$ In a seminal paper, Lalonde (1986) reached pessimistic conclusions regarding the use of non-experimental estimators. Research has since then improved our understanding of how better data makes it possible to avoid the most serious sources of bias. 
${ }^{12}$ Irrelevant covariates may increase bias and/or variance of matching estimators (Caliendo and Kopeinig 2008, Waernbaum 2008). Variables associated with $p$-values above .2 were therefore excluded if not essential for the balancing of the samples.

${ }^{13}$ Further support for our model is that estimates of the returns to higher education, in a companion paper (Stenberg and Westerlund 2013), is only marginally affected by the inclusion/exclusion of military enlistment test scores of cognitive and non-cognitive skills. These variables are available for a sample of males aged 29-39 at the time of enrollment in 1992-1993, altering the estimated returns (1996-2010) by on average less than .2 percentage points in absolute terms.

${ }^{14}$ It is not a problem for our study if treated change their time horizon due to the decision to enroll AE (that is the effect we are after), even if this occurs as early as in connection with the enrollment decision.

${ }^{15}$ The one exception is information on early retirement pensions in 1991 and 1992, but leaving out these variables has only a marginal impact on our estimates.

${ }^{16} \mathrm{By}$ construction, the power of the log-rank tests means the hypothesis of no differences in survival rates may be rejected even though there are point estimates which are not significantly different from zero.

${ }^{17}$ One would perhaps expect treated-untreated differences in early retirement to be larger among females. Compared with males, females' more frequent career interruptions and/or part time employment make the average pensions schemes less generous. Also, the earnings returns to education are typically higher for females, presumably reflecting that there is greater potential for increased work hours (Jacobson et al. 2005a, Stenberg 2011). Both the higher returns and the lower pension schemes of females could increase treated-untreated differences before age 60, but the estimates in Table 3 only weakly indicate such a pattern.

${ }^{18}$ With the extended model, we follow Heckman and Smith (1999) to balance on transitions in labor force status 1990-1991 between employment, unemployment and outside the labor force (OLF), in all nine possible transitions. OLF is defined as annual earnings below SEK 20,000 (app. \$3,000) and no transfers related to unemployment insurance or active labor market programs. Also included are indicator variables of newly married or divorced in 1991 and 1992, changes in status of child at home aged $0-3,4-6$ or 7-10 and amounts of each of the social insurance benefits 1990-1991 and 1991-1992, as well as changes in annual earnings and UI payments 1990-1991.

${ }^{19}$ The estimates for females at ages $61-66$ are very low across all our robustness checks, on average .7 (for males 2.6) with $p$-values of the log-rank test between .49 and .96 (for males, nine tests out of twelve are below .10). The one-to-one matching actually yields relatively similar estimates of males and females (averages of 1.9 and 1.6 and $p$-values of .125 and .150 respectively). To simplify our exposition, the four-to-one matching case is the one exposed in Figure 7. While the one-to-one matching is preferred, the adjacent results still need to be considered.

${ }^{20}$ To avoid exaggerating the impact of delayed retirement on earnings, we assume it is only represented by returns to education which exceed 5 percent for males and 10 percent for females. Assuming returns to education of 3 and 7 percent instead yields sums corresponding to 57 percent for males and 76 percent for females. The average earnings at age 60 refer to those of the matched comparisons. 
${ }^{21}$ With a three percent discount rate, we calculate the present value at age 42 of the earnings difference attributable to delayed retirement. Given the average earnings at age 42, we extrapolate a percentage increase in earnings streams over 25 years (going forward in time) which produces a similar present value. The percentages stated are based on treated completing some tertiary education. The returns increase slightly if one uses the full sample of treated.

\section{Competing interests}

The IZA Journal of European Labor Studies is committed to the IZA Guiding Principles of Research Integrity. The authors declare that they have observed these principles.

\section{Acknowledgement}

The authors gratefully acknowledge financial support of The Swedish Research Council, under Linneaus Grant number 2006-21576-36119-66, through the Ageing and Living Condition (ALC) program at Umeå University and the Bank of Sweden Tercentenary Foundation.

Responsible editor: Alan Barrett

\section{Author details}

${ }^{1}$ SOFI, Stockholm University, SE-10691, Stockholm, Sweden. '2Department of Economics, Umeå University, SE-901 87, Umeå, Sweden.

Received: 23 August 2013 Accepted: 9 October 2013

Published: 07 Nov 2013

\section{References}

Altonji J (1993) The demand for and return to education when education outcomes are uncertain. J Labor Econ 11 (1):48-83

Arulampalam W, Booth LA, Bryan MA (2004) Training in Europe. J Eur Econ Assoc 2(2-3):346-360

Ashenfelter O (1978) Estimating the effeect of training program son earnings. Rev Econ Stat 60:47-57

Autor DH, Levy F, Murnane R (2003) The skill content of recent technological change: an empirical exploration. Q J Econ CXVIII:1279-1333

Autor DH, Katz LF, Kearney M (2008) Trends in U.S. wage inequality: revising the revisionists. Rev Econ Stat 90(2):300-323

Bartel AP, Sicherman N (1993) Technological change and retirement decisions of older workers. J Labor Econ 11(1):162-183

Battistin E, Brunello G, Comi S, Sonedda D (2013) Work Longer, Train More? The Effects of Pension Reforms and Training Incentives on the Retirement and Training Decsions of Older Workers in Italy. Mimeo, Dep. of Economics and Management, University of Padova

Becker GS (1993) Human Capital: A Theoretical and Empirical Analysis with Special Reference to Education, 3rd edition. Chicago University Press, Chicago

Ben-Porath Y (1967) The production of human capital and the life cycle of earnings. J Polit Econ 75(1):352-365

Black DA, Smith JA (2004) How robust is the evidence on the effects of college quality? evidence from matching. J Econ 121:99-124

Blau D (2005) Labour force dynamics of older Men. Econometrica 62(1):117-156

Blau D, Goodstein R (2010) Can social security explain trends in labor force participation of older Men in the United States? J Hum Resour 45(2):328-363

Brunello G (2003) On the Complementarity between Education and Training in Europe. In: Checchi C, Lucifora C (ed) Education, Training and Labour Market Outcomes in Europe. Palgrave MacMillan. http://www.palgraveconnect. com/pc/doifinder/10.1057/9780230522657

Caliendo M, Kopeinig S (2008) Some practical guidance for the implementation of propensity score matching. J Econ Surv 22(1):31-72

Cameron S, Heckman J (2001) The dynamics of educational attainment for black, Hispanic and white males. J Polit Econ 2001:455-499

Comay Y, Melnik A, Pollatschek MA (1973) The option value of education and the optimal path for investment in human capital. Int Econ Rev 14(2):421-435

de Luna X Johansson P (2010) Matching estimators for the effect of a treatment on survival times. J Stat Plan Infer 140(7):2122-2137

Denton F, Spencer B (2009) What is retirement? a review and assessment of alternative concepts and measures. Can J Aging 28(1):63-76

Diaz JJ, Handa S (2006) An assessment of propensity score matching as a nonexperimental impact estimator. J Hum Resour XLI(2):319-345

Dustmann C, Ludsteck J, Schoenberg U (2009) Revisiting the German wage structure. Q J Econ 124(2):843-881

Eklöf M, Hallberg D (2004) Private alternatives and early retirement programs. Working paper 2004:5. Department of Economics, Uppsala University

Eklöf M, Hallberg D (2010) Do buy-outs of older workers matter? estimating retirement behavior with special early retirement offers. Int J Manpow 31(3):337-359

EU (2007) Raising productivity growth. Key messages from the European Competetiveness Report 2007. Communication from the Commission, Brussels 
EU (2008) A European Economic Recovery Plan. Communication from the Commission, Brussels

Fouarge D, Schils T (2009) The effect of early retirement incentives on the training participation of older workers. Labour 23(1):85-109

Fredriksson P, Johansson P (2008) Dynamic treatment assignment - the consequences for evaluations using observational data. J Bus Econ Stat 26(4):435-445

Goos M, Manning A (2007) Lousy and lovely jobs: the rising polarization of work in Britain. Rev of Econ Stat 89:118-133

Goos M, Manning A, Salomons A (2009) Job polarization in Europe. Am Econ Rev 99(2):58-63

Hairault JO, Langot F, Sopraseuth T (2010) Distance to retirement and Old Workers' employment: the case for delaying the retirement Age. J Eur Econ Assoc 8(5):1034-1076

Hazan M (2009) Longevity and lifetime labor supply: evidence and implications. Econometrica 77(6):1829-1863

Heckman J, LaLonde R, Smith J (1999) The Economics and Econometrics of Active Labor Market Programs. In: Ashenfelter O, Card D (ed) Handbook of Labor Economics, 3Ath edition, vol 31

Heckman J, Smith J (1999) The Pre-programme earnings Dip and the determinants of participation in a social programme. Implications for simple programme evaluation strategies. Econ J 109:313-348

Heckman J, Urzua S (2008) The Option Value of Educational Choices And the Rate of Return to Educational Choices. University of Chicago, Mimeo

Iwahashi R (2007) A theoretical assessment of regional development effects on the demand for general education. Econ Educ Rev 26(3):387-394

Jacobson LS, LaLonde RJ, Sullivan DG (2005a) The returns to community college schooling for displaced workers. J Econ 125(1-2):271-304

Jacobson LS, LaLonde RJ, Sullivan DG (2005b) The impact of community college retraining on older displaced workers: should We teach Old dogs New tricks? Ind Labor Relat Rev 58(3):397-415

Kalwij A, Vermeulen F (2005) Labour Force Participation of the Elderly in Europe: The Importance of Being Healthy. IZA discussion paper 1887, Bonn

Karlström A, Palme M, Svensson I (2004) A dynamic programming approach to model retirement behavior of bluecollar workers in Sweden. J Appl Econ 19:795-807

Killingsworth M (1982) Learning by doing" and "investment in training": a synthesis of two "rival"models of the life cycle. Rev Econ Stud XLIX:263-271

Kristensen N (2012) Training and Retirement. IZA Discussion Paper No. 6301, Bonn

LaLonde R (1986) Evaluating the econometric evaluations of training programs with experimental data. Am Econ Rev 76:604-620

Maestas N, Zissimopoulos JM (2010) How longer work lives ease the crunch of population aging. Forthcoming J Econ Pers 24(1):139-160

Magnac T, Pistolesi N, Roux S (2013) Post schooling human capital investments and the life cycle variance of earnings. IZA Discussion Paper No. 7407, Bonn

Monks J (1998) The effect of uncertain returns on human capital investment patterns. Atl Econ J 26(4):413-419

OECD (1998) MaintainingProsperity in an Aging Society. OECD, Paris

OECD (2001) Ageing and income: Financial resources and retirement in 9 OECD countries. OECD, Paris

Peracchi F, Welch F (1994) Trends in labor force transitions of older men and women. J Labor Econ 12(2):210-242

Pissarides C (2011) Regular education as a tool of counter-cyclical employment policy. Nordic Econ Pol Rev 1:207-232

Rosenbaum P, Rubin D (1983) The central role of the propensity score in observational studies for causal effects. Biometrika 70(1):41-55

Smith J, Todd P (2005) Does matching overcome LaLonde's critique of non-experimental estimators? J Econ 125:305-353

Spitz-Oener A (2006) Technical change, job tasks and rising educational demands: looking outside the wage structure. J Labor Econ 24(2):235-270

Stenberg A (2011) Using longitudinal data to evaluate publicly provided formal education for Low-skilled. Econ Educ Rev 30(6):1262-1280

Stenberg A, Westerlund O (2008) Does comprehensive education work for the unemployed? Labour Econ 15(1):54-67

Stenberg A, Westerlund O (2013) Flexibility at a Cost - Should Governments Stimulate Higher Education for Adults? Mimeo, presented at EALE 2012 and ESPE 2012

Stenberg A, De Luna X, Westerlund O (2011) Does Formal Education for Older Workers Increase Earnings? Analyzing Annual Data Stretching over 25 Years. SOFI Working Paper 8/2011. Stockholm University. Resubmitted for revision to Labour

Stenberg A, de Luna X, Westerlund O (2012) Can adult education delay retirement from the labor market? J Popul 25 (2):677-696

Stock JH, Wise DA (1990) Pensions, the option value of work, and retirement. Econometrica 58(5):1151-1180

Waernbaum I (2008) Covariate selection and propensity score specification in causal inference. PhD Thesis, Statististical Studies 38. Department of Statistics, Umeå University

Wallace TD, Ihnen LA (1975) Full-time schooling in life-cycle models of human capital accumulation. J Polit Econ 83:137-155

Warner J, Pleeter S (2001) The personal discount rate: evidence from military downsizing programs. Am Econ Rev 91(1):33-53

Weiss Y (1971) Learning by Doing and Occupational Specialization. J Econ Theory 3(2):189-198

10.1186/2193-9012-2-16

Cite this article as: Stenberg and Westerlund: Education and retirement: does University education at mid-age extend working life? IZA Journal of European Labor Studies 2013, 2:16 